\title{
Constructions of Nonagency in the Clients' Initial Problem Formulations at the Outset of Psychotherapy
}

\author{
Heidi Toivonen ${ }^{1}\left[\right.$ ] Jarl Wahlström ${ }^{1} \cdot$ Katja Kurri $^{2}$
}

Published online: 11 February 2019

(c) The Author(s) 2019

\begin{abstract}
This multiple case study investigated how clients construct nonagentic positions when formulating their problems in the beginning of their first psychotherapy session. The initial problem formulations of nine clients entering psychotherapy were analyzed with a detailed model drawing on discursive methodology, the 10 Discursive Tools model (10DT). We found ten problem formulation categories, each one distinguished by the tool from the 10DT model primarily used to construct nonagency. All clients gave several problem formulations from different categories and constructed nonagentic positions with a variety of discursive tools. When the resulting problem formulation categories were read in comparison with the descriptions of the client's stance at the outset of psychotherapy as presented in two change process models, the Assimilation of Problematic Experiences Sequence and the Innovative Moments Coding System, some similarities were found. However, the 10DT model brought out much variation in the client's nonagentic positioning in the formulations, forming a contrast with the more simplified presentations of the client's initial nonagency given in the change process models. Therapists should pay close attention to how clients express their sense of lost agency at the outset of psychotherapy and how this positions both the client and the therapist as future collaborators in psychotherapy.
\end{abstract}

Keywords Agency $\cdot$ Discursive research $\cdot$ First psychotherapy session $\cdot$ Nonagency $\cdot$ Problem formulations

\section{Introduction}

People seek psychotherapy when encountering problems they cannot solve on their own. This has been conceptualized as an experience of a lost or diminished sense of agency (Adler 2012, 2013; Wahlström 2006). It is suggested that the central task in counseling and psychotherapy is the work on clients' agency problems and advancing their sense of agency (Avdi et al. 2015; Williams and Levitt 2007).

In this qualitative multiple case study, we approach clients' problem formulations as discursive descriptions of

Heidi Toivonen

hktoivon@gmail.com

Jarl Wahlström

jarl.wahlstrom@jyu.fi

Katja Kurri

katja.s.kurri@gmail.com

1 Department of Psychology, University of Jyväskylä, PO Box 35, 40014 Jyväskylä, Finland

2 Private Practice, Mannerheimintie 40 a 24, 00250 Helsinki, Finland nonagency, the feeling of losing mastery in some realm of one's life. The descriptions are studied from a post-psychological point of view, framing lost agency as a languagemediated phenomenon constructed in interaction in a specific situation (e.g., McLeod 2006). Displaying nonagency entails both referring to the substance (i.e., the clients' actual experience of having lost agency in their lives) and the process of psychotherapy (i.e., the seeking of a position in the situational context). The experience of lost agency is not reduced to a mere linguistic presentation, but our aim is to examine how clients achieve the institutionally framed objective of presenting themselves as having problems and hence, being in a nonagentic position (Wahlström and Seilonen 2016).

The clients' presenting problems have typically been explored using categorizations and diagnostic language (e.g. Heafner et al. 2016). However, for understanding the therapeutic change process, such content-based categories are of limited interest, in contrast to portraying how clients position themselves with respect to their problems (Avdi 2012, 2016; Leiman 2012). 


\section{The Client's Stance at the Outset of Therapy}

Psychotherapy change process models, such as the Assimilation of Problematic Experiences Sequence (Stiles 2001; Stiles et al. 2006) and the Innovative Moments Coding System (Gonçalves et al. 2010, 2011), attempt to describe how change occurs in the ways clients relate to their problematic experiences. Both models, using different terminology, display clients as entering therapy in a situation that is somehow restricted, depicting the client as suffering from lack of diversity and flexibility in his/her options for thinking, experiencing, and acting (Gonçalves et al. 2014).

According to the Assimilation of Problematic Experiences Sequence, clients enter therapy with experiences that are psychologically unavailable, avoided, or unclearly formulated because they have not yet been accessed, specified, understood, and integrated into previous experiences (Honos-Webb and Stiles 1998; Stiles et al. 2006). Clients mostly start therapy at levels 2 or 3 (Pérez-Ruiz and Caro Gabalda 2016; Mendes et al. 2016). At level 2, there is only vague awareness of a problematic experience, but at level 3 , the client can more clearly describe it, enabling the client to "have" the problem instead of identifying with it (Honos-Webb and Stiles 1998).

In the Innovative Moments Coding System, clients are depicted as initially being under the rule of a problemsaturated, restricting self-narrative, which during therapy is gradually transformed through innovative moments, displays of new understanding and actions that challenge the dominating narrative (Gonçalves et al. 2010; Montesano et al. 2017). The refined Innovative Moments Coding System groups the innovative moments at two levels, where the first one concerns creating distance from the problem and the second centers on the elaboration of change processes without referring to the problem discourse (Gonçalves et al. 2017; Montesano et al. 2017).

The models suggest that at the beginning of the therapeutic process the client is immersed in a problematic narrative (e.g. Gonçalves et al. 2010) or bound by a silenced problematic experience (Honos-Webb and Stiles 1998). The models construct the therapy process as establishing contact with and communication among different experiences, taking distance from the problem and formulating it more clearly, looking at it from a metaperspective, and finally, consolidating these reconceptualizations in a larger context (Barbosa et al. 2018; Gonçalves et al. 2014). These descriptions of the client's stance at the outset of therapy resonate with the notion of the client's so-called object position, in which the client feels beleaguered by the problem or acted upon by it (Leiman 2012; Todd 2014). During the course of therapy, through adopting an observer point of view, the object position is supposed to evolve into an empowered stance, a subject position (Leiman 2012).

In earlier studies (Toivonen et al. 2018a, b) we referred to the expressed stance of limited action possibilities as the discursive display of loss of one's sense of agency. We presented a detailed, conceptually and empirically grounded classification system, the 10 Discursive Tools model (10DT). The model, empirically based on the same data as this study, conceptualizes agency/nonagency ascription as a discursive, constructive act being performed on two dimensions: (non) agency and (non)reflectivity. The model includes ten pairs of discursive devices named tools, consisting of an agentic and a nonagentic tool, with which the speaker's utterance can construct an agentic or a nonagentic discursive position for the speaker or for the addressee. The notion of "tools" is a metaphor to underline the viewpoint that assuming a nonagentic position is an active discursive deed.

On the agency-nonagency dimension of the 10DT model, the speaker's utterance expresses his/her stance as an able or unable actor, and on the reflectivity-nonreflectivity dimension, the utterance expresses either a reflective or nonreflective stance towards the description of the speaker as an actor. Nonreflectivity comprises a position of solely telling how things are and reporting on the problem as a matter-of-fact, whereas a reflective position entails an observing relation towards the action or lack of action displayed. In the 10DT model, the nonagentic positions are organized from nonreflective statements of not being able to e.g. launch a desired action to more reflective positions of e.g. not understanding why one keeps doing something.

In this study, using the 10DT model, we ask what kind of problem formulations the clients give as a response to the therapists' opening question at the beginning of the first therapy session, when the client is invited to tell what brought him or her to therapy. We seek to give a detailed description of what kind of nonagentic positions become constructed for the clients in relation to their problems in their initial formulations. We also ask how these problem formulations resonate with the descriptions of the client's stance as being immersed in problems given by the process models referred to above.

\section{Problems as Situational and Discursive Constructions}

Problem construction entails situational and discursive positioning in a context where problem talk is expected and invited (Buttny 2004; Wahlström and Seilonen 2016). Positioning refers to how people in situated talk take a stance in relation to aspects of their experience and life events, thereby creating different positions for themselves and others (Davies and Harré 1990; Wahlström 2016). Discursive 
approaches have suggested that the aim of therapy is to enhance clients' ability to flexibly adopt various subject positions (Avdi 2016; Avdi and Georgaca 2009).

In the first session of psychotherapy, clients are expected to indicate a need for help with something constructed as a problem (Wahlström and Seilonen 2016), hence, describe situations where they either do not initiate actions they wish to, or where they undertake actions not expected nor wished for by themselves (Wahlström 2006). In these descriptions, the clients adopt nonagentic positions, that is, stances where the speaker's possibilities to influence situations are depicted as reduced in respect to some aspects of one's life, situation, experiences, or actions (Wahlström 2016).

In the present study, using the 10DT model, we explored how clients, when presenting their self-defined problems, constructed different nonagentic self-ascriptions. We were interested in describing the rich variety of nonagentic selfpositioning presented in the data. The data consisted of the clients' initial problem accounts, the first problem tellings provided at the very beginning of their first session when replying to therapists' opening questions, which entailed more specific reasons or explanations for entering therapy, problem formulations.

\section{Methods}

\section{Participants and Data}

The primary data were the first sessions of nine individual psychotherapies, available from the video-archive of a university-based integrative psychotherapy training program in Finland. The length of the therapies varied from 19 to 78 sessions. The clients were aged between 19 and 45, and eight of them were female and one was male. The nine sessions were conducted by five trainee therapists, all clinical psychologists with a minimum of 2 years of clinical experience. In one case the first session was conducted in tandem by an experienced therapist and a trainee. In two sessions there was a psychology student observing. All clients were self-referred, and no inclusion or exclusion criteria were used in this naturalistic setting. The problems the clients had reported when booking the session included fatigue, stress, social anxiety, panic attacks, depression, coping with divorce, and binging and purging. The sessions were conducted in Finnish. Videotaping and the use of the sessions for research purposes took place with the informed consent of the clients, using a protocol reviewed by the Ethics Committee of the university.

The analysis was performed on the original Finnish transcriptions. The clients' initial problem accounts were first extracted from the verbatim transcriptions of the videotaped sessions. The word counts of the excerpts coded varied between 71 and 1037. The accounts were responses to the therapists' initial questions and prompts, which varied in terms of what the therapists asked and how explicit was the assumption that the clients should explain why they were in therapy. The therapists' questions were open-ended, and often not very clear. The questions entailed the therapist asking about the client's reason for calling the clinic or the client's views of his/her problems (e.g., "If you would first talk about this problematics and its development, such as how it has been constructed?'). In one case the therapist's question was an invitation to talk about oneself ("Shall we begin so that you say something about this situation for which you are seeking help and a little bit about yourself?"). In two cases the therapist did not ask an initial question because the client either presented it himself (e.g., "Well it would probably be good if I shortly say who I am and how I actually got here") or started to cry at the beginning of the session, hence, the reasons given for crying became the client's problem account.

The clients' problem accounts formed one longer, fairly uninterrupted talk turn. They ended when the clients either clearly moved away from the problem telling to a different topic, or the therapist asked or commented on something in a way that did not encourage the client to elaborate on his/her original problem account, but led him/her in another direction. Then, the client's answer was not a clear continuation of the original problem telling. In five sessions, the client replied to the therapist's intervening question or comment by clarifying something, but still continued the initial depiction of the problematic situation. These types of therapist turns were thus not taken as signifying the end of a client's problem account. The data analysis did not include the therapists' responses and comments, generally sparse and short, within the clients' problem accounts. The extracts presented in this article have been translated into English and in some cases slightly stylized to make them more readable. The clients are named with pseudonyms.

\section{The 10DT Model}

The model consists of 10 discursive tools that have two sides each: an agency tool (AT) and a nonagency tool (NAT), with which either an agentic or nonagentic position can be ascribed to speakers or to addressees. Using ATs or NATs, speakers display either a reflective or nonreflective relation to the description of themselves as an actor. Clients can take a position that is simultaneously agentic but nonreflective or nonagentic but reflective (Toivonen et al. 2018a). When presenting their problems, the clients display problematic or lacking agency by using the nonagency tools of the model.

In Table 1, the NATs are given on the left, the equivalent ATs are next to them in parentheses, and the definitions of 
Table 1 Summary of the discursive tools of nonagency

\begin{tabular}{|c|c|}
\hline Nonagency tool (NAT) & Short definition \\
\hline 1. Dismissing (accepting) & $\begin{array}{l}\text { The problem is unrelated to oneself, any meaningful personal relationship with a supposed } \\
\text { problem is denied or mitigated }\end{array}$ \\
\hline 2. Other as actor (free to act) & $\begin{array}{l}\text { Some phenomenon/event is functioning as the actor, the client's position is either unverbalized/ } \\
\text { hidden or that of a victim, object, or stooge }\end{array}$ \\
\hline 3. Exteriorization (interiorization) & Experiences exist as their own entities and are not one's own creation \\
\hline 4. Not initiating action (initiating action) & Not being able to initiate action \\
\hline $\begin{array}{l}\text { 5. Not stopping or curbing action (stopping or } \\
\text { curbing action) }\end{array}$ & Not being able to stop what one is doing \\
\hline 6. Not modifying action (modifying action) & Not being able to make constructive choices \\
\hline 7. Noncognizance (cognizance) & Not understanding, knowing, noticing, etc. something about one's experiences \\
\hline 8. Reflected dysfunction (reflected function) & Having assumed a problematic way of relating to one's experiences or dealing with problems \\
\hline 9. Discontinuance (continuance) & The current actions/experiences are not meaningfully related to the past/future \\
\hline $\begin{array}{l}\text { 10. Presumptive positioning of others (per- } \\
\text { spectival positioning of others) }\end{array}$ & $\begin{array}{l}\text { Not taking into account other person's perspective and being unable to coordinate meanings in a } \\
\text { situation }\end{array}$ \\
\hline
\end{tabular}

the NATs are on the right. For the purposes of readability, the definitions of the ATs are not given here.

The order of the NATs and ATs represents the increasing reflectivity towards one's experiences and actions as the number of the tool grows. The nonreflective tools (1 to 6) ascribe a position from which the problems are only reported on. With the reflective tools (7 to 10), an observing position is ascribed, from which the client's thoughts, experiences, or life events are looked at. The NATs run from a total mitigation and denial of any problems whatsoever through displays of problems in launching, stopping, or modifying action to pondering positions towards one's own understanding, previous ways of acting, life story, or social relations. The tools are identifiable in short excerpts of talk, occasionally involving only a few words.

\section{Analytic Procedure}

The analysis focused on the previously defined first problem accounts and started by identifying problem formulations, understood as semantically independent reasons given for attending therapy, within them. The formulations were often separated from each other in the clients' talk by short expressions such as "and well then" or "but well." Each problem formulation usually consisted of one utterance, in some instances of two or three, that concerned the same situation or phenomenon constructed as a problem. First, the utterance forming the main statement or central point of the formulation was identified, and the tool with which the client's nonagentic position was constructed, was coded as the main tool. Next, the other utterance(s) including complementary information and statements supporting the main point were identified and the nonagentic expressions in them were coded as side tools.
Every problem formulation included at least one nonagentic tool, thus identified as the main NAT. There was not a side tool in all formulations of a certain category. If the same NAT was used in several successive utterances within the same problem formulation, they were counted as one instance of the tool in question. Below is an example of how the main tool and the side tool can look like in the constitution of one formulation:

And then somehow the summer went so that not a sin-

gle day went by without me thinking about the return

to work (NAT5) (but then somehow it went) and it

kind of like increased all the time like soon it's getting

closer (NAT2).

The client first describes how she could not stop worrying about returning to work, coded with NAT5 (not stopping or curbing action), a tool with which the speaker takes the position of not being able to stop a specific action. The part within brackets was read as a short agentic expression, as the summer is displayed to have passed in some way despite the client's nervousness. The last expression provides complementary information on her worrying about the return and shows the nervousness as the actor that increases on its own, coded with NAT2 (other as actor). Often, the expression coded to include the main tool was underlined by the speaker with verbalizations such as "above all" and/or came first in the utterance, followed by the extra information provided by expression/expressions where the nonagentic tool was classified as a side tool. The first author made the first suggestions of what was the main position and which were the less important positions, constructed with which NATs, and the coding was subsequently refined by all three authors together.

Occasionally, there was also neutral talk within the utterance (i.e., talk that did not concern the clients' problems in 
any way). In addition, there were in the clients' talk, both between the problem formulations and in some cases also within them, agency ascriptions, that is, expressions where the clients constructed themselves as agents using agency tools. As the focus of this analysis was on nonagency construction, and because the agency ascriptions were few and did not differentiate the problem formulations, they were not coded or included in the final analysis.

As a second step in the analysis, the problem formulations were categorized.

In their problem accounts, the clients hardly ever presented only one single, clearly defined problem. Hence, each client's account included several problem formulations and a large variety of nonagentic positions. The categorization of the formulations was done bottom-up from the data, as formulation categories, differing in terms of how the client's failing agency became displayed, started to evolve from the data. The categorization of the problem formulations was not based on the psychological content of the problems, nor on details of vocabulary, but on how the discursive construction of nonagency was performed using different NATs. In all of the formulations of the same category, the main NAT was the same. Also, it was noticed that the same NAT could be used in different ways to create the impression of failing agency. The difference was recognized for instance in grammatical details such as what/who was the subject of the sentence. As such linguistic nuances created slightly different versions of the nonagentic position associated with the particular NAT in use, it became evident that categorically different kinds of formulations could be constructed with the same NAT. The categories emerging from the analysis were named according to the particular quality of the problem, as produced with the respective NATs constructing the client's nonagentic position.

\section{Credibility Check}

The close reading of the data, the coding of the verbatim transcriptions with the 10DT model, and the preliminary categorization of the problem formulations was done by the first author. The coding and the categorization were reviewed and modified in consensus meetings by all three authors, with full access to the data. The final decision on the coding of the data and the categorization of the formulations was usually achieved in full agreement by all three authors, but in more difficult questions, the agreement of the first author and one of the other authors was considered sufficient.

\section{Results}

Sixty-three problem formulations were identified and classified into ten problem formulation categories. Out of the ten nonagency tools of the 10DT model, the first eight were found in the problem accounts. All clients used more than one tool in their formulations, and all clients produced more than one problem formulation in their accounts.

Table 2 shows all ten problem formulation categories and the nonagency tool (NAT1 to NAT8) from the 10DT model that was the main tool in the formulations of each category, as well as the other nonagency tools that had a more arbitrary presence as a side tool in some formulations of the category. The order of presentation of the categories is based on the tools used and their place within the 10DT model (see Table 1 above). Note that formulations based on NAT9 or NAT10 were not found. For the name of each tool the reader is advised to consult Table 1 . In the descriptions

Table 2 Problem formulation categories

\begin{tabular}{|c|c|c|c|c|}
\hline Formulation category & The client presented his or her problem to be... & $\mathrm{n}$ & Main tool in all formulations & Side tool \\
\hline 1. Questioned issue & Not real or relevant for therapy & 1 & NAT1, dismissing & 2 \\
\hline 2. Circumstance & $\begin{array}{l}\text { An external situation that he or she was not able to } \\
\text { affect }\end{array}$ & 12 & NAT2, other as actor & $3,6,7$ \\
\hline 3. Active phenomenon & An independent actor causing things to him or her & 11 & NAT2, other as actor & 6,7 \\
\hline 4. Inhibited action & Feeling stuck or unable to start some desired action & 3 & NAT4, not initiating action & 2,6 \\
\hline 5. Uncontrolled action & Acting in an uncontrollable or repetitive way & 8 & NAT5, not stopping or curbing action & $2,6,7$ \\
\hline 6. Changing state & $\begin{array}{l}\text { His or her experience or state changing without him or } \\
\text { her being able to stop it }\end{array}$ & 5 & NAT5, not stopping or curbing action & 3,6 \\
\hline 7. Nonconstructive managing & Not being able to find constructive options for acting & 10 & NAT6, not modifying action & 2,3 \\
\hline 8. Pressured action & Pressure to act in a certain way & 4 & NAT6, not modifying action & 2 \\
\hline 9. Not knowing/misconstructions & $\begin{array}{l}\text { Not knowing about and/or entertaining failing notions } \\
\text { about something }\end{array}$ & 4 & NAT7, noncognizance & 2,3 \\
\hline 10. Poor dealing with problems & $\begin{array}{l}\text { Having previously tried to handle his or her problems } \\
\text { in a way that was not functional }\end{array}$ & 5 & NAT8, reflected dysfunction & $2,3,6$ \\
\hline
\end{tabular}

NAT nonagentic tool 
of the formulation categories below, the name of each tool is given once.

\section{The Problem Formulation Categories}

To save space, we give a data extract to illustrate the formulation categories only of the first (least reflective), the last (most reflective), and of the most common category, the second one.

\section{Questioned Issue}

The client questioned whether the problem was real or suitable for therapeutic work. Nonagency was primarily constructed with NAT1 (dismissing), the tool with which a personal relation to a certain problem is denied or mitigated. There was only one formulation of this type in the data, the one by Anna shown below. When presented at the start of a psychotherapy session, this formulation can be heard so that the client, paradoxically, offers as her problem the feeling that her eating difficulties are not a problem in the first place.

Extract 1, Anna: I have a very sore throat all the time and I of course always have a stabbing pain in my teeth. And then, well, one keeps fainting, and my digestion is totally messed up, and my nails are not growing, and my hair is in bad shape, and all the blood counts are all wrong. Then, of course, my stomach is bulging because of protein deficiency and all, and one does not get enough vitamins (NAT2), but still there is this feeling that why should I go and get any help because basically nothing is wrong, this is just kind of a teenagers' game (NAT1).

The formulation begins with a list of physical problems constructed as independently happening to Anna (NAT2), followed by the main position: a dismissive stance towards the eating problems (NAT1). The tool would also allow for a complete denial of any personal relationship with a problem, but here it is used to mitigate the significance of her problems and thereby to question their relevance for therapy.

\section{Circumstance}

The problem was displayed as an external situation that the client could not change: things are what they are and will keep being that way. Nonagency was primarily constructed with NAT2 (other as actor), with which the circumstance was positioned as the actor and the client was left in an inhibited position. The client displayed him- or herself as merely reacting to or observing circumstances beyond his or her control.
Extract 2, Arja: Somehow what feels difficult is that I have a good psychologist but the intensity is just absolutely too low (NAT2). Every time I have forgotten completely what we have discussed in the previous session (NAT6). It's just like small talk (NAT2).

Previously, Arja has said that she has been seeing a psychologist at the communal mental health services every 2 weeks. Here, she presents the low frequency of the sessions and their insufficient substance as facts that just exist as if she has no opportunity to change them (NAT2). Arja also takes a position where she cannot help but forget what has been talked about in the sessions (NAT6).

\section{Active Phenomenon}

The problem was the client's experience, behavior, or some incident in his or her life that acted as agent. Nonagency was primarily constructed with NAT2, displaying the client as the object of whatever was occurring in his or her life. The client's thoughts, feelings, actions, physical symptoms, diagnoses, memories, or life events took the place of the grammatical subject, and there was hardly any reference to the client-speaker with personal pronouns or first-person verb forms. Differing from the previous category, in this one the problem was not depicted as a situation existing "out there" but as a phenomenon or force, in the wide sense of the word, which acted in the client or in his or her life.

\section{Inhibited Action}

The problem entailed the client being unable to launch a desired action. Nonagency was primarily constructed with NAT4 (not initiating action), which is the first of those three tools in the 10DT model where the position taken concerns the clients' action (NATs 4 to 6). There is a qualitative difference between Formulation Categories 1 to 3 (based on NATs 1 to 2), where the client's problem becomes formulated as some outside actor or phenomenon, and Formulation Categories 4 to 8 (based on NATs 4 to 6 ), where the problem has to do with how the client acts.

\section{Uncontrolled Action}

The problem was that the client could not stop doing something. Nonagency was primarily constructed with NAT5 (not stopping or curbing action). The client's action was depicted as out of control with passive verb forms, a dramatic presence, or zero-person constructions, which in Finnish is an impersonal, nonspecific person reference type with neither an overt subject of the action nor explicit references to any persons (Jokela 2012; Laitinen 1995). Time was also 
referred to using phrases such as "all the time" and "there wasn't a single day when I didn't (do something)."

\section{Changing State}

The client's state or condition was depicted as changing in an autonomous process. Nonagency was primarily constructed with NAT5, with which the client positioned oneself as not able to control the said process happening in him or her, instead of presenting oneself as doing something that he or she could not stop, as in the previous category. In the original Finnish expressions, reflexive verb forms were often used, that is, forms indicating that the action happens to the person enacting the action.

\section{Nonconstructive Managing}

The client was having trouble dealing with something such as side symptoms or nervousness. Nonagency was primarily constructed with NAT6 (not modifying action), and the client was displayed as not able to change his or her action to handle some situation properly or as wondering how to "survive" of a certain situation.

\section{Pressured Action}

The client displayed being faced with a difficult situation where the options for acting are limited, or where he or she feels pressure to act in a certain way. Nonagency was primarily constructed with NAT6, depicting the clients as not able to adjust their actions either because of their concrete situation or a psychologically experienced "must".

\section{Not Knowing/Misconstructions as Problem}

These formulations concerned the client's displayed lack of understanding or knowledge concerning a previous situation in life or a current one. Nonagency was primarily constructed with NAT7, which functioned to create a position of lacking knowledge or perception with regards to one's own experience or circumstances.

\section{Poor Dealing with Problems}

The clients' earlier, perhaps still undergoing, attempts at dealing with something or ways of relating to their issues had become part of the problem. Nonagency was primarily constructed with NAT8 (reflected dysfunction), with which clients took a critical stance towards their previously assumed way of handling their problems. This way was thus, at least implicitly, presented as in need of replacement with a better one in therapy. The difference between the previous category is that here, the clients look from a critical standpoint at a way of relating to their problem (NAT8), representing a sort of discursive metaposition, instead of merely presenting a belief or thought as not accurate (NAT7) as in the previous category.

Extract 3, Tiina: Now one didn't really have enough strength to handle the problems or be with them alone (NAT8). [I thought one should try and fix one's head.] (T: um are you able to capture the feeling that came to you?) So [now I'm feeling a bit like perhaps even relieved but] one has been so horribly tired of this thing one has and of what has happened. One gets tired of going over these things again and again (NAT8).

Tiina's earlier way of relating to her problems-when she tried to "handle" them, "be with them," or "go over them again and again"-is presented as problematic because it led to her exhaustion. With NAT8, a nonagentic reflective position is constructed: the client is in an observing relation to her nonagency, not managing one's life crisis in an efficient way. As Tiina says that she has been alone with her problems, a new way to act is welcomed and the therapist invited as a companion in its creation. The parts within square brackets are displays of agency, as Tiina positions herself as wanting to get help from therapy. The objectifying verbalization "this thing one has" is part of the client's display of her way of relating to the problem as problematic.

\section{Discussion}

\section{Summary of Results}

In this qualitative multiple case study, we asked how clients discursively constructed for themselves nonagentic positions when formulating their problems at the beginning of their first session of psychotherapy. Using the 10DT model of discursive agency construction (Toivonen et al. 2018a, b), the nonagentic positions were identified and coded according to which nonagency tool was in use in constructing the positions. The nonagentic positions were taken within different problem formulations the clients gave in their problem accounts when responding to the therapists' initial questions. Sixty-three problem formulations were found and categorized to ten problem formulation categories based on which nonagency tool (NAT) from the 10DT model primarily contributed in constructing the nonagentic position and how, discursively speaking, this was done.

In the problem formulations, the nonagency tools from NAT1 to NAT8 were all in use at least once, but NAT9 and NAT10 were not in use in any. In most formulation categories, there were, in addition to the NATs, agentic and reflective tools in use in the formulations. Only in Formulation Category 1 (questioned issue), there were solely nonagentic 
and nonreflective tools in use, thus, no agentic and/or reflective positions were constructed.

All nine clients gave formulations from at least two different categories, and one client gave formulations from five. Six clients gave at least one problem formulation where nonagency was primarily constructed with a reflective tool. Three clients did not give formulations where nonagency was constructed with a reflective tool. These three clients differed in age and background and presented different kinds of issues.

The semantic content of the problem formulations did not determine how the nonagentic position was ascribed. The clients could ascribe to themselves both an agentic and a nonagentic position, and a reflective and a nonreflective position in respect to the same problem. The variety of formulations given, in terms of topics, and of how the nonagentic position was ascribed by singular clients, was too large to allow any other classification of the clients according to these, except for the before mentioned group of three clients who only constructed formulations with nonreflective tools.

In the formulations constructed with nonreflective NATs, the clients seemed to merely report their experiences "with little sense of subject" (Kennedy 1997, p. 557) and without reflecting on them in a context. The formulations constructed with reflective NATs displayed the client's nonagency as stemming from not knowing or not understanding something and in them, the clients displayed having already done therapy-relevant work before coming to therapy. The nonagentic but reflective position afforded clients to present themselves as somehow failing in agency in some realm of their lives, but simultaneously as being observant of this.

In Formulation Categories 1 to 3 (nonagency primarily constructed with NATs 1 to 2), the problem became displayed as concerning some external factor or phenomenon; in Formulation Categories 4 to 8 (nonagency primarily constructed with NATs 4 to 6), the problem was displayed as concerning the clients' difficulty in managing their actions; in Formulation Categories 9 to 10 (nonagency primarily constructed with NATs 7 to 8 ), the problem was displayed as concerning the clients' own understanding.

\section{Comparison with the Change Process Models}

The notion that clients come to psychotherapy in an immersed, subjugated, or object position in relation to their problematic experiences does receive partial support in this study. The clients did occasionally position themselves as being overwhelmed by their issues. However, this occurred only in Formulation Categories 2 (circumstance) and 3 (active phenomenon) where, with NAT2 (other as actor) the problem was positioned as the actor who was "doing" things on its own, leaving the client in the position of an object or victim. Even in these formulations, though, the clients occasionally also used agentic and reflective tools that obscured the object position. Furthermore, such an object position was primary in only two formulation categories (2 and 3). Our findings do not support the implicit assumption that the client could not look at the problem from a distance or take a position that expresses active agency right from the beginning of therapy.

The Assimilation of Problematic Experiences Sequence and the Innovative Moments Coding System imply that there is mostly no reflectivity in a client's stance at the outset of therapy (Gonçalves et al. 2014; Stiles 2001), in line with the notion of an object position which implies that the client cannot look at the problem from a reflective position (Leiman 2012). In this study, however, reflective tools were used to construct positions in many problem formulations in several categories, starting from Formulation Category 2 (circumstance). In Formulation Categories 9 to 10, the nonagentic position was primarily constructed with a reflective tool, displaying the client as looking at the problem critically or ponderingly. These results suggest that the concept of object position is more multifaceted than has previously been acknowledged and could perhaps be best understood as an umbrella term, comprised of a multiplicity of nonagentic positioning that forms a situationally invited and useful discursive resource in psychotherapy.

The problem formulations and their descriptions of failing agency have convergences with how the client's initial stance is presented in the change process models. To mention a few resemblances, in the Assimilation model (Stiles et al. 2006) level 0 (warded off) implies that the client is unaware of the problem. It resembles Formulation Category 1 (questioned issue), where the client took a mitigating position and questioned the existence of a therapy-relevant problem. This formulation type appeared only once, in Anna's session, among her other problem formulations from altogether five different categories.

The Innovative Moments Coding System presents innovative moments as new intentional actions diverging from what the problematic narrative impels the client to do (Gonçalves et al. 2010). These notions resemble positions taken with ATs within problem formulations, as clients expressed things they have been able to think and do despite the problem. New understanding was often displayed also with reflective NATs, taking a critical or wondering position towards a problem.

\section{Clinical Implications}

The variation of nonagentic self-ascriptions in the problem formulations has implications for therapeutic collaboration. Formulation Category 1 (questioned issue), where clients mitigate their reasons for coming to therapy, is challenging, as the whole reason for coming to therapy 
is dismissed. Formulation Categories 2 (circumstance) and 3 (active phenomenon) display the clients' problems as external and challenge the therapist to invite clients to describe them as psychological phenomena from a more experiential position. In Formulation Categories 4 to 8 the therapist is invited to work on the client's maladaptive action patterns. In Formulation Categories 9 (not knowing/misconstructions as problem) and 10 (poor dealing with problems), clients specifically identify what has not worked for them and thus, present a more advanced invitation for therapists to join them in finding more constructive stances to their problems.

\section{Limitations and Future Directions}

The limitations of this study include the preliminary nature of the 10DT model which prevents us from giving reliability and validity of the concept of NAT. The problem formulation categories found are small in frequency, and even though they were well differentiated from each other, the limited space allowed to describe them may compromise the reader's full appreciation of their differences. The limitations of the study also include the small data of only nine sessions and the fact that the clients were only one male and all were Finnish.

This study shows that the general idea of the client entering therapy in a demoralized state is more complex than has been previously understood. The 10DT model showed to be a fruitful method in revealing the richness of the positions the clients take in their early problem formulations. This study contributes to the approaching of the clients' initial problem formulations by showing them as more multifaceted and reflected upon than e.g. the process models seem to indicate.

We encourage clinicians to listen not only from the perspective of content (what the client is talking about) but also from the perspective of discursive presentation (how the client positions him- or herself in relation to various phenomena). Therapists are invited to pay attention to which of the clients' positions they address in their turn and how they do this, as their responses open up ways to construct and reconstruct the positionings in relation to the clients' problems.

Funding Open access funding provided by University of Jyväskylä (JYU). This work was supported by the Department of Psychology, University of Jyväskylä under Grants 1/13.00.04.00/2015 and 1/13.00.04.00/2017.

\section{Compliance with Ethical Standards}

Conflict of interest The authors report no conflicts of interest.
Open Access This article is distributed under the terms of the Creative Commons Attribution 4.0 International License (http://creativeco mmons.org/licenses/by/4.0/), which permits unrestricted use, distribution, and reproduction in any medium, provided you give appropriate credit to the original author(s) and the source, provide a link to the Creative Commons license, and indicate if changes were made.

\section{References}

Adler, J. M. (2012). Living into the story: Agency and coherence in a longitudinal study of narrative identity development and mental health over the course of psychotherapy. Journal of Personality and Social Psychology, 102, 367-389. https://doi.org/10.1037/ a0025289.

Adler, J. M. (2013). Clients' and therapists' stories about psychotherapy. Journal of Personality, 81, 595-605. https://doi.org/10.111 $1 /$ j.1467-6494.2012.00803.x.

Avdi, E. (2012). Exploring the contribution of subject positioning to studying therapy as a dialogical enterprise. International Journal for Dialogical Science, 6(1), 61-79.

Avdi, E. (2016). Positioning as embodied interaction: Commentary on Guilfoyle. Journal of Constructivist Psychology, 29(2), 141-148. https://doi.org/10.1080/10720537.2015.1034816.

Avdi, E., \& Georgaca, E. (2009). Narrative and discursive approaches to the analysis of subjectivity in psychotherapy. Social and Personality Psychology Compass, 3, 654-670. https://doi.org/10.11 11/j.1751-9004.2009.00196.x.

Avdi, E., Lerou, V., \& Seikkula, J. (2015). Dialogical features, therapist responsiveness, and agency in a therapy for psychosis. Journal of Constructivist Psychology, 28, 329-341. https://doi. org/10.1080/10720537.2014.994692.

Barbosa, E., Couto, A. B., Basto, I., Stiles, W. B., Pinto-Gouveia, J., \& Salgado, J. (2018). Immersion and distancing during assimilation of problematic experiences in a good-outcome case of emotionfocused therapy. Psychotherapy Research, 28(2), 313-327. https ://doi.org/10.1080/10503307.2016.1211347.

Buttny, R. (2004). Talking problems: Studies of discursive construction. Albany: State University of New York Press.

Davies, B., \& Harré, R. (1990). Positioning: The discursive production of selves. Journal for the Theory of Social Behavior, 20, 43-63. https://doi.org/10.1111/j.1468-5914.1990.tb00174.x.

Gonçalves, M. M., Caro Gabalda, I., Ribeiro, A. P., Pinheiro, P., Borges, R., Sousa, I., \& Stiles, W. B. (2014). The innovative moments coding system and the assimilation of problematic experiences scale: A case study comparing two methods to track change in psychotherapy. Psychotherapy Research, 24(4), 442455. https://doi.org/10.1080/10503307.2013.835080.

Gonçalves, M. M., Mendes, I., Ribeiro, A. P., Angus, L. E., \& Greenberg, L. S. (2010). Innovative moments and change in emotionfocused therapy: The case of Lisa. Journal of Constructivist Psychology, 23(4), 267-294. https://doi.org/10.1080/10720 537.2010.489758.

Gonçalves, M. M., Ribeiro, A. P., Mendes, I., Alves, D., Silva, J., Rosa, C., Oliveira, J. T. (2017). Three narrative-based coding systems: Innovative moments, ambivalence and ambivalence resolution. Psychotherapy Research, 27(3), 270-282. https://doi. org/10.1080/10503307.2016.1247216.

Gonçalves, M. M., Ribeiro, A. P., Mendes, I., Matos, M., \& Santos, A. (2011). Tracking novelties in psychotherapy process research: The innovative moments coding system. Psychotherapy Research, 21(5), 497-509. https://doi.org/10.1080/10503307.2011.560207.

Heafner, J., Silva, K., Tambling, R. B., \& Anderson, S. R. (2016). Client-reported-presenting problems at an MFT Clinic. The 
Family Journal: Counseling and Therapy for Couples and Families, 24(2), 140-146. https://doi.org/10.1177/1066480716628581.

Honos-Webb, L., \& Stiles, W. B. (1998). Reformulation of assimilation analysis in terms of voices. Psychotherapy, 35(1), 23-33.

Jokela, H. (2012). Nollapersoonalause suomessa ja virossa: tutkimus kirjoitetun kielen aineistosta. [Zero person sentences in Finnish and Estonian: A study on data in written language]. Annales Universitatis Turkuensis C 334. (Doctoral dissertation, University of Turku, Finland).

Kennedy, R. (1997). On subjective organizations: Toward a theory on subject relations. Psychoanalytic Dialogue: The International Journal of Relational Perspectives, 7, 553-581. https://doi. org/10.1080/10481889709539205.

Laitinen, L. (1995). Nollapersoona. [Zero-person construction]. Virittäjä 99, 337-358. Retrieved from http://elektra.helsinki.fi.ezpro xy.jyu.fi/se/v/0042-6806/99/3/nollaper.pdf.

Leiman, M. (2012). Dialogical sequence analysis in studying psychotherapeutic discourse. International Journal for Dialogical Science, 6, 123-147.

McLeod, J. (2006). Narrative thinking and the emergence of postpsychological therapies. Narrative Inquiry, 16, 201-210. https://doi. org/10.1075/bct.6.24mcl.

Mendes, I., Rosa, S., Stiles, W. B., Gabalda, C., Gomes, I., Basto, P., I., \& Salgado, I. (2016). Setbacks in the process of assimilation of problematic experiences in two cases of emotion-focused therapy for depression. Psychotherapy Research, 26(6), 638-652. https:// doi.org/10.1080/10503307.2015.1136443.

Montesano, A., Oliveira, J. T., \& Gonçalves, M. M. (2017). How do self-narratives change during psychotherapy? A review of innovative moments research. Journal of Systemic Therapies, 36(3), 81-96.

Pérez-Ruiz, S., \& Caro-Gabalda, I. (2016). Assimilation of problematic experiences in Brief Strategic Therapy: Olivia and her fear of dying / La asimilación de experiencias problemáticas en la Terapia Breve Estratégica: Olivia y su miedo a morir. Estudios de Psicología, 37(2-3), 311-343. https://doi.org/10.1080/02109 395.2016.1204785.

Stiles, W. B. (2001). Assimilation of problematic experiences. Psychotherapy, 38(4), 462-465. https://doi. org/10.1037/0033-3204.38.4.462.
Stiles, W. B., Leiman, M., Shapiro, D. A., Hardy, G. E., Barkham, M., Detert, N. B., \& Llewelyn, S. P. (2006). What does the first exchange tell? Dialogical sequence analysis and assimilation in very brief therapy. Psychotherapy Research, 16(4), 408-421. https ://doi.org/10.1080/10503300500288829.

Todd, N. (2014). Between subject and object: Using the grammar of verbs to enhance the therapeutic construction of personal agency. Journal of Constructivist Psychology, 27, 289-302. https://doi. org/10.1080/10720537.2013.843479.

Toivonen, H., Wahlström, J., \& Kurri, K. (2018a). Constructing nonagency at the beginning of psychotherapy: The 10DT model. Journal of Constructivist Psychotherapy. https://doi. org/10.1080/10720537.2018.1433088.

Toivonen, H., Wahlström, J., \& Kurri, K. (2018b). Discordances in ascriptions of agency and reflectivity given to clients in the first psychotherapy session. Journal of Constructivist Psychotherapy. https://doi.org/10.1080/10720537.2018.1515048

Wahlström, J. (2006). The narrative metaphor and the quest for integration in psychotherapy. In E. O`Leary \& M. Murphy (Eds.), New approaches to integration in psychotherapy (pp. 38-49). London: Routledge.

Wahlström, J. (2016). Constructing the moral order of a relationship in couples therapy. In M. Borcsa \& P. Rober (Eds.), Research perspectives in couple therapy: Discursive qualitative methods (pp. 149-165). London: Springer.

Wahlström, J., \& Seilonen, M.-L. (2016). Displaying agency problems at the outset of psychotherapy. European Journal of Psychotherapy \& Counselling, 18(4), 333-348. https://doi.org/10.1080/13642 537.2016.1260616.

Williams, D. C., \& Levitt, H. M. (2007). Principles for facilitating agency in psychotherapy. Psychotherapy Research, 17, 66-82. https://doi.org/10.1080/10503300500469098.

Publisher's Note Springer Nature remains neutral with regard to jurisdictional claims in published maps and institutional affiliations. 